\title{
The open-ocean sensible heat flux and its significance for Arctic boundary layer mixing during early fall
}

\author{
Manisha Ganeshan ${ }^{1}$ and Dong L. $\mathrm{Wu}^{2}$ \\ ${ }^{1}$ Goddard Earth Sciences Technology and Research Studies and Investigations, USRA, Greenbelt, MD 20771, USA \\ ${ }^{2}$ NASA Goddard Space Flight Center, Greenbelt, MD 20771, USA \\ Correspondence to: Manisha Ganeshan (mganeshan@usra.edu)
}

Received: 29 October 2015 - Published in Atmos. Chem. Phys. Discuss.: 8 March 2016

Revised: 22 August 2016 - Accepted: 15 September 2016 - Published: 27 October 2016

\begin{abstract}
The increasing ice-free area during late summer has transformed the Arctic to a climate system with more dynamic boundary layer (BL) clouds and seasonal sea ice growth. The open-ocean sensible heat flux, a crucial mechanism of excessive ocean heat loss to the atmosphere during the fall freeze season, is speculated to play an important role in the recently observed cloud cover increase and BL instability. However, lack of observations and understanding of the resilience of the proposed mechanisms, especially in relation to meteorological and interannual variability, has left a poorly constrained BL parameterization scheme in Arctic climate models. In this study, we use multiyear Japanese cruise-ship observations from R/V Mirai over the open Arctic Ocean to characterize the surface sensible heat flux (SSHF) during early fall and investigate its contribution to BL turbulence. It is found that mixing by SSHF is favored during episodes of high surface wind speed and is also influenced by the prevailing cloud regime. The deepest BLs and maximum ocean-atmosphere temperature difference are observed during cold air advection (associated with the stratocumulus regime), yet, contrary to previous speculation, the efficiency of sensible heat exchange is low. On the other hand, the SSHF contributes significantly to BL mixing during the uplift (low pressure) followed by the highly stable (stratus) regime. Overall, it can explain $\sim 10 \%$ of the openocean BL height variability, whereas cloud-driven (moisture and radiative) mechanisms appear to be the other dominant source of convective turbulence. Nevertheless, there is strong interannual variability in the relationship between the SSHF and the BL height which can be intensified by the changing occurrence of Arctic climate patterns, such as positive surface wind speed anomalies and more frequent conditions of
\end{abstract}

uplift. This study highlights the need for comprehensive BL observations like the R/V Mirai for better understanding and predicting the dynamic nature of the Arctic climate.

\section{Introduction}

The recent decline of the Arctic sea ice during late summer (August-September) has raised several questions for the new climate system, for example, the response of boundary layer (BL) clouds and the feedback to sea ice recovery. Turbulent heat fluxes over the ice-free ocean are expected to play an important role under these circumstances. The aim of this study is to provide a better understanding of the role of surface sensible heat flux (SSHF) in the formation of oceanic $\mathrm{BL}$ and dissipating ocean heat to the atmosphere during late summer and early fall.

Model simulations of the 21st century climate have suggested that even if the Arctic Ocean were to become completely ice-free in summer, the loss of excess heat to the atmosphere through enhanced ocean (sensible and latent) heat fluxes during October-December months would enable the recovery of sea ice (Tietsche et al., 2011). Ship-based observations during the fall of 2010 have similarly indicated the importance of the ocean sensible heat flux for the onset of the annual freeze cycle (Inoue and Hori, 2011). The authors suggested that the cold air outbreak in the wake of cyclogenesis enabled significant cooling of the upper ocean (and freeze onset; Inoue and Hori, 2011). Presently, however, there is limited observational guidance for the open-ocean heat fluxes and the efficiency of turbulent heat exchange during such events. 
The rapid sea-ice retreat in recent years has also raised speculation that the increased air-sea temperature gradients may contribute to reduced BL stability and associated cloud changes (Kay and Gettelman, 2009; Schweiger et al., 2008). For example, observations from satellites (Kay and Gettelman, 2009; Wu and Lee, 2012) and ground stations (Eastman and Warren, 2010) suggest a general increase in the low cloud cover over the ice-free Arctic Ocean during fall, especially in regions of reduced atmospheric stability (Kay and Gettelman, 2009). Studies have also shown an increase in the mid-level cloud cover (and simultaneous decrease in low clouds) indicating a deepening of the Arctic BL (Sato et al., 2012; Schweiger et al., 2008; Palm et al., 2010). This has also been attributed mainly to the enhanced air-sea temperature difference and resulting upward sensible heat flux (Sato et al., 2012; Schweiger et al., 2008). Despite the observed cloud changes, no direct measurements have been made to quantify the open-ocean surface fluxes or its influence on BL mixing. As this area continues to increase in a warmer climate, it becomes more important to fully understand and characterize the changes in cloud cover and the underlying BL processes.

Observations over sea ice show that mixing in the Arctic BL is primarily driven by clouds and cloud-top radiative cooling (Tjernström et al., 2004; Inoue et al., 2005; Morrison et al., 2011; Shupe et al., 2013), which can be more significant than surface turbulent fluxes (Curry et al., 2000; Morrison et al., 2012; Shupe et al., 2013; Nicholls and Leighton, 1986). Such a BL represents the situation arising from strongly insulating sea ice that prevents efficient turbulent heat exchange at the surface. Over the open ocean, the air-sea interaction can be more pronounced. For example, it has been suggested that surface heat and moisture fluxes lead to BL "roll" clouds during cold air outbreak events over the open Arctic Ocean (Klein et al., 2009). In this study, using multi-year ship-based observations, we investigate the variability of the open-ocean sensible heat flux, and more importantly its contribution to BL mixing (and turbulent heat exchange) under varying weather (and cloud) regimes.

\section{Datasets}

Surface and upper-air meteorological data from the icestrengthened research vessel (R/V Mirai) operated by the Japan Agency for Marine-Earth Science and Technology are analyzed in this study. The vessel surveyed the icefree regions mainly in the vicinity of Beaufort and Chukchi seas (from $125^{\circ} \mathrm{W}$ to $175^{\circ} \mathrm{E}$ longitude and between 60 and $80^{\circ} \mathrm{N}$ latitude). Data were collected during September and early October of the years 2002 (Fujiyoshi and Shimada, 2002), 2004 (Fujiyoshi and Shimada, 2004), 2008 (Kurita and Yoneyama, 2008), 2009 (Inoue and Yoneyama, 2009), 2010 (Inoue, 2010) and 2013 (Inoue, 2013). On account of the retreating sea ice, recent observations were collected in

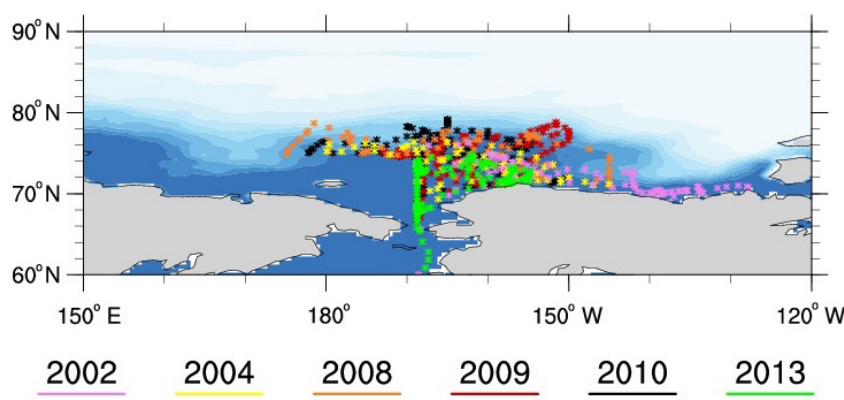

Figure 1. Ship tracks during multi-year cruises of the R/V Mirai indicated by colored asterisk symbols. The average ice fraction (shaded white) at the time of cruise during 2008-2010 is also shown based on National Centers for Environmental Prediction/National Center for Atmospheric Research (NCEP/NCAR) reanalyses project (Kalnay et al., 1996).

more northern latitudes compared to earlier years (Fig. 1; Sato et al., 2012; Inoue and Hori, 2011). The year 2013, however, is an exception when observations were primarily collected at a fixed point $\left(72.75^{\circ} \mathrm{N}\right.$ and $\left.168.25^{\circ} \mathrm{W}\right)$ as part of the Arctic Research Collaboration for the Radiosonde Observing System (ARCROSE) experiment (Inoue et al., 2015; Kawaguchi et al., 2015). The radiosonde data include profiles of temperature, pressure, winds, and relative humidity, typically sampled at 3 to $12 \mathrm{~h}$ intervals with vertical resolution ranging from $40 \mathrm{~m}$ in the lower levels to around $70 \mathrm{~m}$ in the mid-troposphere. In order to exclude the near-surface contamination due to warming and cooling of the ship body, a minimum height threshold of $100 \mathrm{~m}$ is imposed to ensure quality data of the atmospheric profiles.

Also used in the R/V Mirai data analysis are independent, quality-controlled observations of surface meteorological variables, viz. $10 \mathrm{~min}$ average values of sea surface temperature (SST), surface air temperature (SAT), surface pressure, and surface horizontal wind speed $\left(V_{\text {surf }}\right)$. The SAT and $V_{\text {surf }}$ are measured at 21 and $25 \mathrm{~m}$ above sea level, respectively. These measurements are used to estimate the SSHF at the time of radiosonde launches. A total of 876 contemporaneous samples of BL structure and SSHF (excluding missing data) are analyzed from all cruises. Thus, this dataset provides a unique and valuable survey of Arctic BL properties over the open ocean (Fig. 1), complementing other observational efforts carried out mainly on the central polar ice pack (Tjernström et al., 2004; Shupe et al., 2013) and coastalcontinental Arctic regions (Eastman and Warren, 2010).

\section{Methods}

\subsection{Estimation of surface sensible heat flux}

The product of the wind speed, and the temperature difference between the sea surface and overlying air $(\Delta T)$, is a common estimate of the SSHF (Fairall et al., 1996; Bourassa 


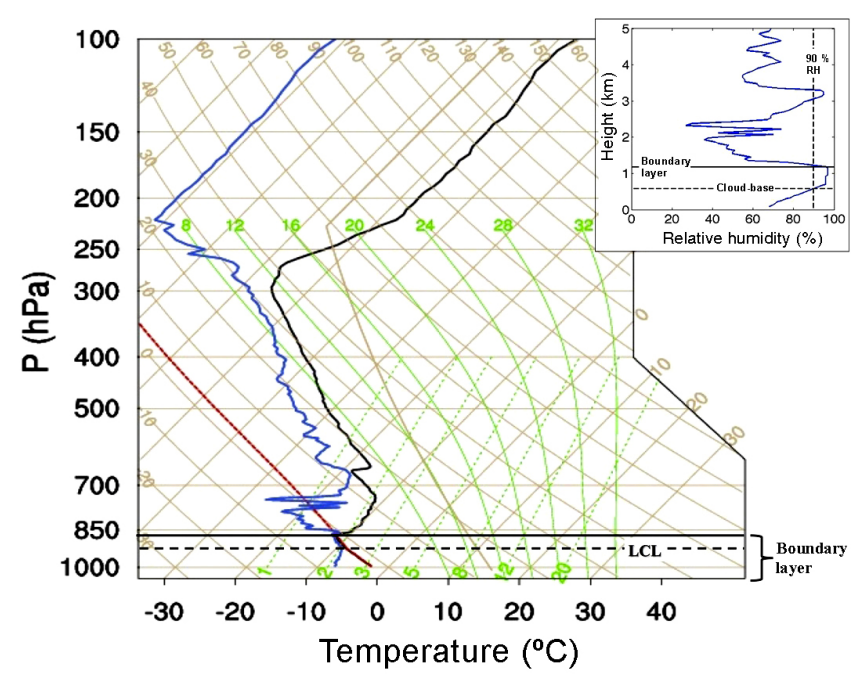

Figure 2. Skew $T$-log $P$ diagram denoting the profiles of environmental temperature (black) and dew point temperature (blue) observed at 09:00 Z, 21 September 2013. The red dashed line represents the adiabatic ascent of a surface-based parcel. The solid horizontal black line is the boundary layer (BL) height determined using the parcel-based method, whereas the dashed horizontal black line represents the lifting condensation level (LCL); and (inset) a close examination of the relative humidity in the lowest $5 \mathrm{~km}$, where the dashed vertical line represents the $90 \% \mathrm{RH}$ threshold, the dashed horizontal line is the cloud base, and the solid horizontal line represents the BL. (For detailed description on the components of a skew $T$ - $\log P$ chart, refer to the Air Weather Service technical report titled AWS/TR-79/006, The Use of the Skew T, Log P Diagram in Analysis and Forecasting, December 1979, revised March 1990.)

et al., 2010; Inoue et al., 2011). In this study, the SSHF is calculated using the following equation:

$\mathrm{SSHF}=\rho C_{p} C_{H} V_{\text {surf }}(\Delta T)$,

where $\Delta T=\mathrm{SST}-\mathrm{SAT},{ }^{\circ} \mathrm{C}, V_{\text {surf }}=$ surface horizontal wind speed, $\mathrm{m} \mathrm{s}^{-1}, \rho=$ air density, $\mathrm{kg} \mathrm{m}^{-3}, C_{p}=$ specific heat capacity of air, $\mathrm{J} \mathrm{kg}^{-1} \mathrm{~K}^{-1}$, and $C_{H}=$ transfer coefficient for SSHF (based on winds measured at $20 \mathrm{~m}$ height).

The values of the constants $\rho, C_{p}$, and $C_{H}$ are adopted from Inoue et al. (2011). Based on Eq. (1), positive values of SSHF will indicate upward SSHF (from the ocean to the atmosphere).

\subsection{Determination of $B L$ height}

The height of the well-mixed BL is calculated using the parcel-based method, as illustrated in Fig. 2. In this method, a surface parcel is assumed to ascend along a dry adiabat up to the lifting condensation level (LCL), and along a moist adiabat thereafter (denoted by red dashed line in Fig. 2). There is no striking difference in the slopes of the dry and moist adiabats in Fig. 2, as they are nearly parallel in a cold environment. The height of the BL is computed as the level where the parcel temperature falls below the environment temperature by a value of $0.6 \mathrm{~K}$ or more. For most soundings, this level is coincident with the cloud top or the base of the temperature inversion (as shown in Fig. 2). To comprehend the complex Arctic BL processes, we also examine the influence of BL clouds as described in the following subsection.

The BL over the open Arctic Ocean is found to be mixed or neutral ( $>90 \%$ of the time), in agreement with Sato et al. (2012). The wind speed variance in the BL is typically less than $30 \%$ of the mean, suggesting negligible mechanical turbulence for most cases. The Arctic BLs, thus, appear to be primarily mixed by convective fluxes. In a well-mixed BL, the surface turbulent fluxes decrease linearly with height (Holton, 2004). Hence, we examine the correlation between the SSHF and the BL height on a profile-by-profile basis. A good correlation implies that the SSHF controls the convective turbulence in the BL. In the case of a poor correlation, factors such as cloud or moisture driven turbulence may influence the BL height (Morrison et al., 2012; Shupe et al., 2013). We investigate the BL cloud statistics as described below. Note that a bottom-up approach is used to identify the BL top, which ensures that clouds identified within the BL are always coupled to the surface.

\subsection{Estimation of BL cloud thickness ratio}

Based on past studies over sea ice, the Arctic is found to be mostly cloudy, and the cloud-driven turbulence is known to control the BL height variability (Tjernström et al., 2004; Shupe et al., 2013). Low clouds coupled to the BL may generate convective turbulence from above (Curry et al., 2000; Morrison et al., 2012; Shupe et al., 2013), thereby weakening the correlation between the SSHF and BL height. It is therefore important to consider the effect of BL clouds in this study. For this purpose, the BL cloud thickness ratio is calculated as the percentage ratio of cloud layer within the BL. The cloud base is defined as the first layer above the surface where the relative humidity (RH) equals $90 \%$ or more (as in Sato et al., 2012), and the cloud layer is calculated as the vertical integral of all layers within the BL that exceed $90 \%$ RH. As an example, for the profile shown in Fig. 2 (inset), the cloud base and BL heights are calculated as 580 and $1180 \mathrm{~m}$ respectively, and the BL cloud thickness ratio is estimated to be $\sim 50 \%$.

\section{Results}

\subsection{Characteristics of SSHF over the open Arctic Ocean}

Figure 3 shows the distribution of the SSHF, the temperature gradient between sea surface and air $(\Delta T)$, and the surface wind speeds $\left(V_{\text {surf }}\right)$, based on multi-year observations. The lack of meaningful differences in the yearly SSHF median values suggests that its interannual variability is not signifi- 
(a)

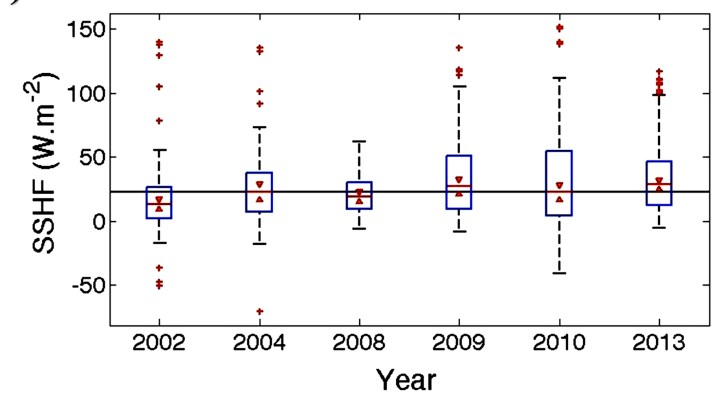

(b)

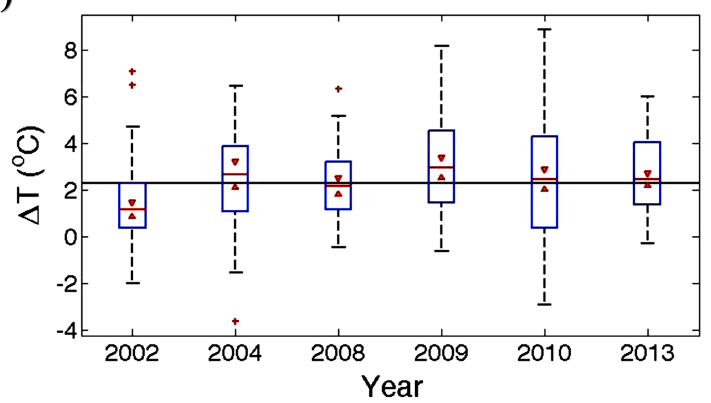

(c)

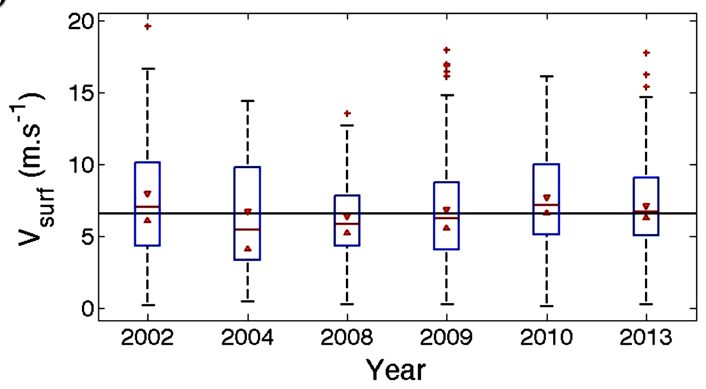

Figure 3. The interannual variability in the distribution of (a) the surface sensible heat flux (SSHF), (b) ocean-atmosphere temperature gradient $(\Delta T)$, and (c) surface wind speeds $\left(V_{\text {surf }}\right)$. The solid horizontal black line represents the overall median value based on 6 years of ship data. The median for each year is represented by the horizontal red line within each boxplot, and the red notches represent the $95 \%$ confidence intervals around the same. Two medians are different at the $5 \%$ significance level if their intervals do not overlap.

cant at the $95 \%$ confidence level. The correlation between SSHF and $\Delta T$ (correlation coefficient $=0.77$ ) is found to be higher than that of SSHF and $V_{\text {surf }}$ (correlation coefficient $=0.45$ ). The distribution in Fig. 3a indicates that more positive SSHF values, and a heavier tail (barring outliers), occur in recent years $(2009,2010,2013)$. It appears that more negative SAT values (not shown) may contribute to the broader $\Delta T$ and SSHF distributions observed during 2009 and 2010 (Fig. 3a and b). (In general, the $\Delta T$ appears to be more strongly influenced by SAT rather than SST.)

As the SSHF can be sensitive to the $\Delta T$ variability during fall, it is particularly interesting to explore its relation- (a)

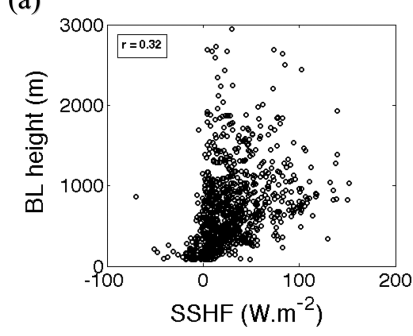

(b)

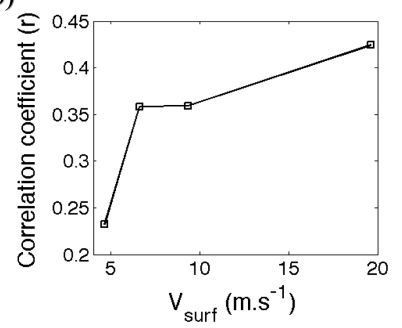

Figure 4. (a) Scatter plot of the SSHF and BL height using all observations based on 6 years of cruise-ship data. The correlation coefficient is denoted by $r$, and (b) $r$ as a function of surface wind speed ( $\left.V_{\text {surf }}\right)$. The data are binned based on the quartiles of $V_{\text {surf }}$, and $r$ is calculated for each bin. The number of observations in each bin is equal to 219 .

ship with negative SATs. In model simulations, the occurrence of cold air advection (CAA) events and increased $\Delta T$ is known to release copious amounts of ocean heat flux and trigger the seasonal recovery of sea ice (Deser et al., 2010; Kolstad and Bracegirdle, 2008). Models also project that future occurrences of CAA may spread further poleward along the retreating sea ice margin (Kolstad and Bracegirdle, 2008). In spite of recent observations and modeling efforts (Inoue and Hori, 2011; Klein et al., 2009), there are limited measurements of actual surface fluxes during such events. In the following sections, using ship-based measurements, we investigate the instantaneous relationship between the SSHF and the BL height, which qualitatively represents the efficiency of turbulent heat exchange between the ocean and the atmosphere.

\subsection{The SSHF contribution to BL mixing}

Figure $4 \mathrm{a}$ shows that a weak positive relationship exists between the SSHF and BL height, which can explain up to $10 \%$ of the BL height variability. Contrary to expectations, this relationship is not found to depend on the oceanatmosphere temperature gradient $(\Delta T)$. Instead, the correlation coefficient $(r)$ is sensitive to the surface wind speeds $\left(V_{\text {surf }}\right.$; Fig. $\left.4 \mathrm{~b}\right)$ suggesting that the surface-generated turbulent mixing is favored during episodes of strong winds and is independent of the $\Delta T \mathrm{~s}$.

Additionally, low-level clouds, which are known to generate turbulence in the Arctic BL, may influence the correlation. Therefore, we closely inspect the behavior of the correlation coefficient $(r)$ under varying cloud regimes in the following subsection.

\subsubsection{Effects of cloud regime}

In the Arctic, large-scale atmospheric processes are mainly responsible for the occurrence and sustenance of low cloud cover (Herman and Goody, 1976; Morrison et al., 2012; 
(a)

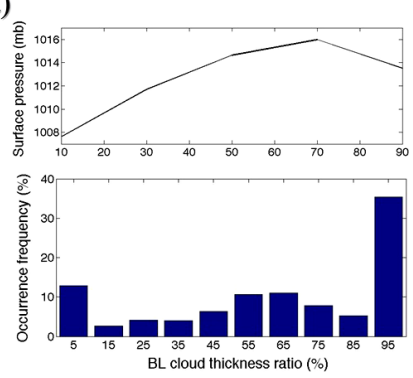

(c)

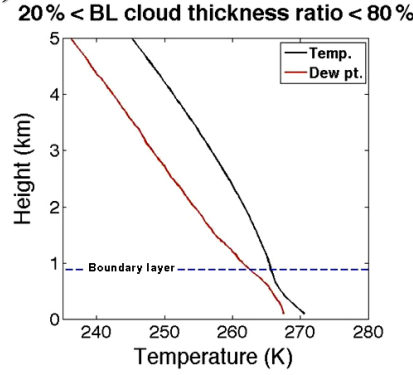

(b)

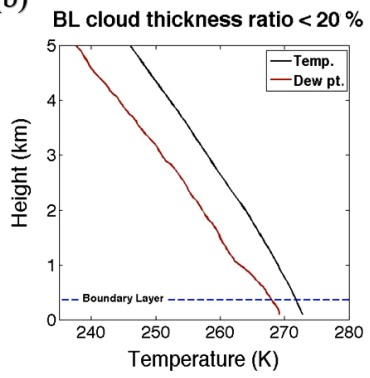

(d)

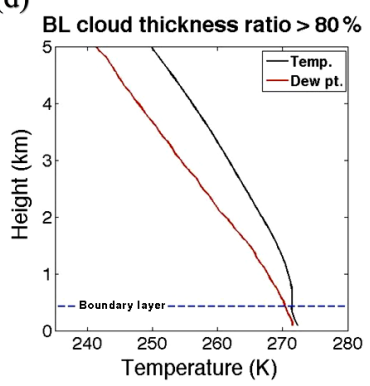

Figure 5. (a) The frequency distribution of BL cloud thickness ratio (bottom panel), and the mean surface pressure for five equally spaced bins of the BL cloud thickness ratio (top panel), and (b) the profiles of mean temperature and dew point temperature observed for cases with BL cloud thickness ratio $\leq 20 \%$, (c) same as (b) but for cases with $20 \%<$ BL cloud thickness ratio $<80 \%$, and (d) same as (b) but for cases with BL cloud thickness ratio $\geq 80 \%$.

Solomon et al., 2014). Barton et al. (2012) recently classified Arctic clouds based on the background dynamic and thermodynamic state of the lower troposphere. They identified four robust meteorological regimes based on the lower tropospheric stability or the potential temperature difference between the surface and $700 \mathrm{mb}\left(\theta_{700}-\theta_{\text {surf }}\right)$, and the $500 \mathrm{mb}$ pressure vertical velocity $\left(\omega_{500}\right)$. The first three regimes have positive $\omega_{500}$ values indicating weak subsidence and differ only in their lower tropospheric stability $\left(\theta_{700}-\theta_{\text {surf }}\right.$; Barton et al., 2012). The fourth atmospheric state comprises the uplift regime (characterized by rising motion or negative $\omega_{500}$ values), which is only found to occur $10-15 \%$ of the time (Barton et al., 2012; Taylor et al., 2015). The subsidence regimes typically have cloud bases within the BL and are characterized by increasing cloud-top/BL height with decreasing stability (Barton et al., 2012). During the uplift regime, on the other hand, the cloud fraction peaks in the free troposphere above the BL (Barton et al., 2012). In our study, the focus is on the BL height variability; therefore, we will not be studying clouds with cloud-base above the BL. Moreover, in lieu of the pressure vertical velocity $\left(\omega_{500}\right)$, we examine the surface pressure to distinguish between the uplift and subsidence regimes.

The bottom panel of Fig. 5a shows the frequency distribution of BL cloud thickness ratio during fall. Three dis-

tinct BL cloud types emerge, with thickness ratios peaking at 5, 65, and $95 \%$ (Fig. 5a). Consequently, the observations are divided into three groups consisting of low $(<20 \%)$, medium $(20-80 \%)$, and high $(>80 \%)$ BL cloud thickness ratios, respectively. Note that threshold pairs other than 20$80 \%$ (such as 10-90 and 25-75\%) were tested for classification purposes, and the results were found to remain robust. Table 1 shows the occurrence frequency, mean surface pressure, and the lower tropospheric stability $\left(\theta_{700}-\theta_{\text {surf }}\right)$ associated with each group, while Fig. $5 \mathrm{~b}-\mathrm{d}$ show the average temperature and moisture profiles. Significantly lower pressure conditions (99\% confidence level) are associated with the low BL cloud thickness group, which occurs roughly $15 \%$ of the time. While upper level clouds may be present, a vast majority of the cases do not have BL clouds (Fig. 5b). Therefore this group is synonymous with the uplift regime described by Barton et al. (2012). On the other hand, the top panel of Fig. 5a suggests that BL clouds are favored in a subsiding environment (high-pressure conditions), consistent with Barton et al. (2012).

For the group with high BL cloud thickness (greater than $80 \%$ ), the relatively strong lower tropospheric stability (Table 1) and shallow BL height (Fig. 5d) indicate that it belongs to the very highly stable-highly stable regime (Barton et al., 2012). Figure $5 \mathrm{c}$ on the other hand shows a deeper BL with moderate stability, suggesting that the group with medium cloud thickness (20 to $80 \%$ ) is similar to the stable regime described by Barton et al. (2012). Note that the occurrence frequency of these two groups (Table 1) also aligns with that of the respective regimes observed during fall (Barton et al., 2012).

A comparison of the lower tropospheric stability and BL (cloud-top) height between both groups (Table 1 and Fig. 5c, d) reveal that they are in fact analogous to the stratocumulus and stratus cloud types. The stable, shallow, and cloudy BL in Fig. $5 \mathrm{~d}$ is characteristic of the stratus cloud regime, whereas the deeper well-mixed BL with higher cloud top (Fig. 5c) represents the stratocumulus-topped BL. Similar distinctions between stratus and stratocumulus Arctic clouds were noted in previous studies as well (Sato et al., 2012). Thus, the low, medium, and high BL cloud thickness groups identified in Table 1 are henceforth referred to as the uplift, stratocumulus, and stratus regimes, respectively. Figure 6 compares the lower tropospheric structure of temperature and moisture for stratus and stratocumulus regimes. Consistent with Sato et al. (2012), it is evident that CAA is mainly responsible for the occurrence of stratocumulus clouds (Fig. 6a), whereas warm and moist air advection (or subsidence) leads to the formation of stratus clouds in the Arctic (Fig. 6).

Table 1 shows the average wind speed, $\Delta T$, and the correlation coefficient $(r)$ between SSHF and BL height, for the three regimes. The wind speeds are comparable, but the $\Delta T$ is significantly higher for the stratocumulus regime ( $99 \%$ confidence level). In the past, there has been speculation that the surface-generated turbulence is enhanced due to strong 
Table 1. The frequency of occurrence, mean surface pressure, mean lower tropospheric stability, mean boundary layer (BL) height, cloud regime, the correlation coefficient $(r)$ between SSHF and BL height, mean temperature difference between ocean and air, and mean surface wind speed, observed for the three different groups of BL cloud thickness ratio (see text and Fig. 5 for explanation). Statistically significant values of $r$ (99\% confidence level) are highlighted in bold.

\begin{tabular}{lrrr}
\hline BL cloud thickness ratio $(\%)$ & $\leq 20$ & 20 to 80 & $\geq 80$ \\
\hline Occurrence frequency $(\%)$ & 15 & 44 & 41 \\
Surface pressure $(\mathrm{mb})$ & 1008 & 1015 & 1014 \\
$\theta_{700}-\theta_{\text {surf }}\left({ }^{\circ} \mathrm{C}\right)$ & 13.6 & 14.9 & 18.1 \\
BL height $(\mathrm{m})$ & 646 & 997 & 508 \\
Cloud regime & Uplift & Stratocumulus (stable) & Stratus (very highly-highly stable) \\
$r$ & $\mathbf{0 . 5 8}$ & -0.04 & $\mathbf{0 . 3 3}$ \\
$\Delta T\left({ }^{\circ} \mathrm{C}\right)$ & 1.76 & 3.41 & 1.71 \\
$V_{\text {surf }}\left(\mathrm{m} \mathrm{s}^{-1}\right)$ & 7.01 & 7.20 & 7.05 \\
\hline
\end{tabular}

(a)

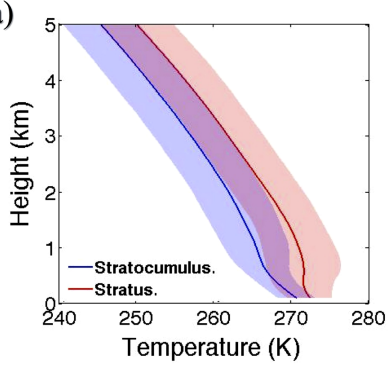

(b)

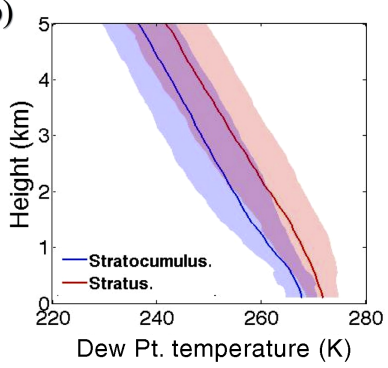

Figure 6. The atmospheric profile comparison between the stratocumulus and stratus regimes. The solid line represents the mean and the shaded area represents the standard deviation of (a) the temperature and (b) the dew point temperature.

air-sea temperature gradients associated with cold air advection over open water (Sato et al., 2012; Kay and Gettelman, 2009). Yet, the weak correlation coefficient $(r)$ for the stratocumulus regime in Table 1 suggests that despite the enhanced $\Delta T$, the SSHF appears to contribute very little to the formation of the deep well-mixed BL (Table 1). Figure 6a shows that the temperature anomaly in this regime is maximized between 0.3 to $1.5 \mathrm{~km}$ altitudes, indicating that cold air advection occurs above the surface, where stratocumulus clouds likely form by the release of latent heat of vaporization. In such a case, the unstable lapse rate is perhaps more strongly driven by cloud condensational processes rather than the SSHF. This will be further explored in Sect. 4.4.

On the other hand, the surface contribution to BL mixing is significant during the uplift regime, as well as in the presence of stratus clouds occurring within a (warm and wet) subsiding environment ( $r$ in Table 1). Other studies have also noted that the influence of surface type (sea ice vs. open water) is more evident for shallow BL clouds occurring in the highly stable (stratus) regime compared to the stable (stratocumulus) regime (Barton et al., 2012; Taylor et al., 2015). In the following subsection, we will more closely examine the re-

(a)

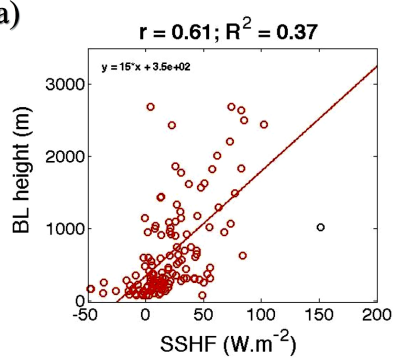

(b)

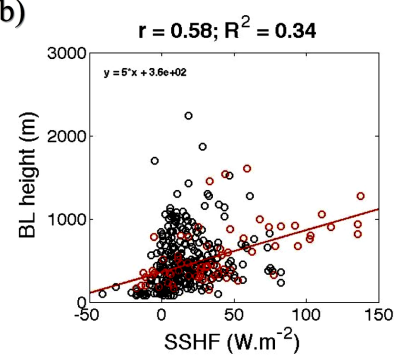

Figure 7. The scatter plot of SSHF and BL height during (a) the uplift regime, and (b) the stratus regime. The linear relationship between the SSHF and BL height derived using the least squares method of curve-fitting for (a) all cases (except one outlier indicated by black marker), and (b) cases with surface wind speeds exceeding $9.8 \mathrm{~ms}^{-1}$ (indicated by red markers). The correlation coefficient and the coefficient of multiple determination for each linear relationship is denoted by $r$ and $R^{2}$, respectively. Note that the outlier in the uplift regime is an observation point with maximum $\Delta T$, which has no influence on $r$. Conversely, the red markers in the stratus regime are observations with maximum surface wind speeds, which have a positive influence on $r$. See Sect. 4.2 for explanation.

lationship between the SSHF and BL height in the uplift and stratus regimes.

\subsubsection{Influence of surface winds}

Figure 7a shows that the SSHF can explain a substantial amount of the BL height variability in the uplift regime (up to $37 \%)$. For the stratus cloud regime, the correlation between SSHF and BL height is already significant (Table 1) but improves substantially during episodes of high $\left(>9.8 \mathrm{~ms}^{-1}\right)$ surface wind speed (Fig. 7b). For the deep, stratocumulustopped BL, the relationship between SSHF and BL height becomes weakly positive $(r=0.14)$ during high surface wind speeds but remains insignificant. Thus, apart from other factors, surface winds are clearly important for generating turbulent heat exchange in the stable Arctic BL. 
Table 2. The average Arctic Oscillation (AO) index observed during the period of the cruise, the correlation coefficient between SSHF and BL height $(r)$, and the number of observations $(n)$, for each cruise year. Statistically significant values of $r$ (99\% confidence level) are highlighted in bold.

\begin{tabular}{lrrrrrr}
\hline Year & 2002 & 2004 & 2008 & 2009 & 2010 & 2013 \\
\hline AO index & -1.16 & 0.08 & 1.21 & 0.29 & 0.51 & -1.50 \\
$r$ & $\mathbf{0 . 6 4}$ & 0.15 & 0.18 & 0.16 & $\mathbf{0 . 5 9}$ & -0.02 \\
$n$ & 100 & 65 & 93 & 131 & 214 & 273 \\
\hline
\end{tabular}

Altogether, based on the linear relationships between SSHF and BL height and the frequency of occurrence of the uplift $(\sim 15 \%)$ and stratus cloud regimes $(\sim 41 \%)$, the surface-generated turbulence may explain up to $10 \%$ of the Arctic BL height variability during fall. The in-cloud moist and radiative processes that are responsible for formation of mixed layers over sea ice (Tjernström et al., 2004; Shupe et al., 2013; Morrison et al., 2012) are likely to be dominant over the open ocean as well. In the following subsection, we examine the interannual variability in the BL height and its relationship to the SSHF.

\subsection{Interannual variability}

As discussed in the previous section (Sect. 4.2.3), the height of the well-mixed Arctic BL is likely controlled by the cloudgenerated turbulence rather than the SSHF. Figure 8 shows the yearly distribution of BL height, BL cloud thickness ratio, and surface pressure, for the period of the cruise. Unlike the SSHF (Fig. 3a), the BL height shows increases in its maximum values during recent years $(2010,2013)$. It also has greater interannual variability as suggested by the significantly shallow BL (95\% confidence level) observed during 2002 (Fig. 8a). The large-scale circulation (sea level pressure distribution) appears to be different during this year (Fig. 8c). The circulation anomaly may have a significant influence on the BL cloud distribution (Fig. 8b), which may consequently impact the BL height variability (Fig. 8a). (This will be elaborated in the following subsection.)

The interannual variability in the correlation coefficient $(r$; Table 2) suggests that the SSHF and BL height relationship is most significant for the years 2002 and 2010 (99\% confidence level). The time series of both quantities indeed confirms the dominant role of surface fluxes in the evolution of the Arctic BL (Fig. 9). The reasons for the same are explored below.

As described in Sect. 4.2, both cloud type and wind speeds may influence the SSHF contribution to BL mixing. The frequency distribution of different cloud regimes and the corresponding surface wind speed anomalies (positive only) are shown for each year in Fig. 10. For the years with positive Arctic Oscillation (Table 2), it is evident that the stratus and stratocumulus regimes dominate the climate. The (a)

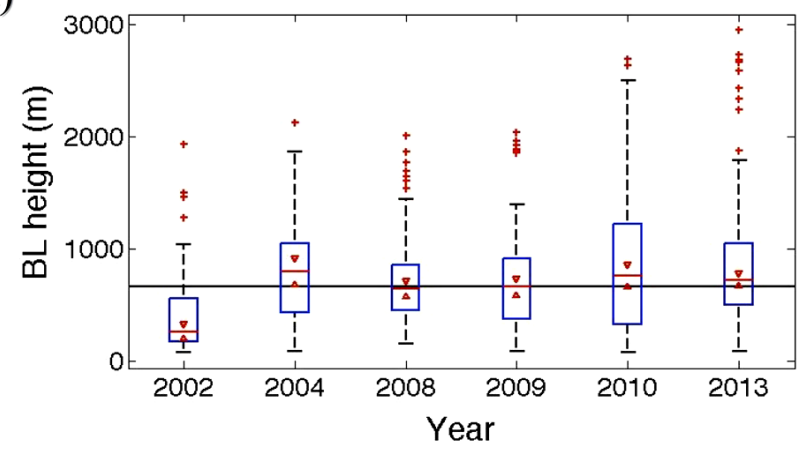

(b)

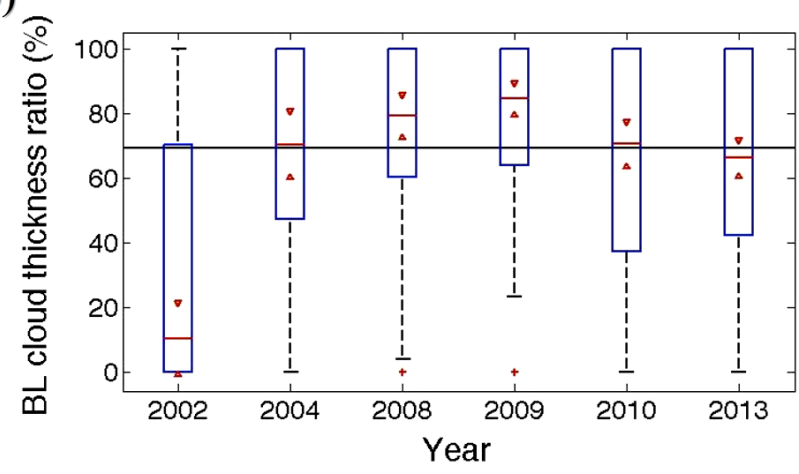

(c)

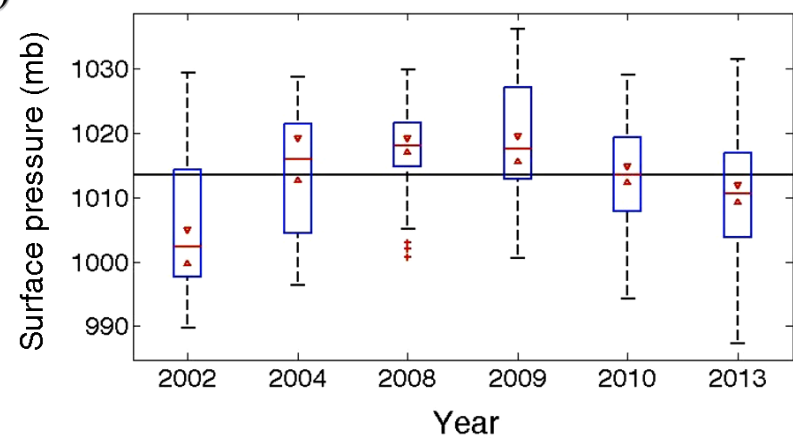

Figure 8. Same as Fig. 3 but for (a) boundary layer height, (b) boundary layer cloud thickness ratio, and (c) surface pressure.

regime distribution is quite different during 2002 and 2013 (both years with negative AO index). The year 2002 is governed by anomalously low surface pressure or the uplift regime, whereas the year 2013 is accompanied by greater than usual occurrence of stratocumulus clouds (bottom panel of Fig. 10). Sampling inconsistency due to spatially restricted (fixed point) observations can also contribute to the anomalous cloud regime distribution observed during 2013. From Fig. 10, it appears that a lower stratocumulus cloud fraction (bottom panel) coupled with higher surface wind speeds in the stratus regime (top panel) contributes to the better correlation between SSHF and BL height during 2002 and 2010 (Table 2). 
(a)

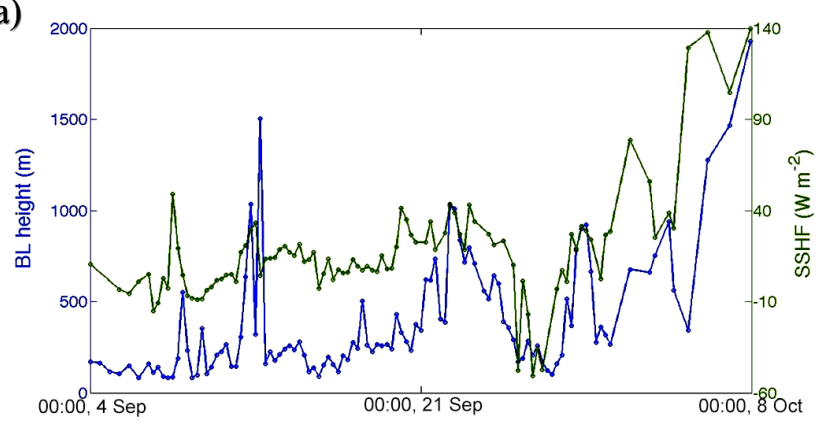

(b)

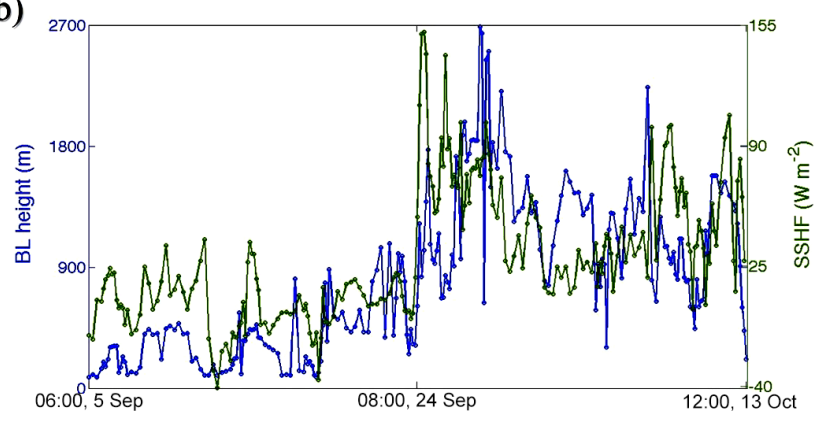

Figure 9. The time series of the boundary layer height (blue line; left axis) and the surface sensible heat flux (green line; right axis) during the period of the cruise in (a) 2002 and (b) 2010. The dots represent the time instances of actual measurements.

Thus, although the SSHF presently controls only $10 \%$ of the BL height variability, the relationship can become stronger under more frequent occurrences of the uplift regime and/or high surface wind speeds associated with the stratus regime. As a result, the changing patterns of future Arctic climate, such as more frequent storms and greater wind stress (Hakkinen et al., 2008; Higgins and Cassano, 2009; Smedsrud et al., 2011), may act to enhance the oceanatmosphere coupling. In the following section, we will further evaluate the relative roles of SSHF and clouds in atmospheric mixing based on BL thermodynamics.

\subsection{BL thermodynamics over the open Arctic Ocean}

The contribution of SSHF to BL mixing is better understood by examining its role in the thermodynamic equation (Eq. 2).

$$
\int_{0}^{\mathrm{BL}} \frac{\partial T}{\partial t}+\int_{0}^{\mathrm{BL}} \bar{V} \nabla T+\int_{0}^{\mathrm{BL}}\left(\Gamma_{\text {adiabat }}-\Gamma_{\mathrm{env}}\right) w=\int_{0}^{\mathrm{BL}} \frac{Q}{c_{p}}
$$

(A)

(B)

(C)

(D),

where (A) is time rate of change in local temperature, (B) the horizontal temperature advection in the BL, and (C) the product of the vertical velocity and the difference between the adiabatic and environment lapse rates. (D) is diabatic heating (cooling) caused by surface turbulent fluxes,
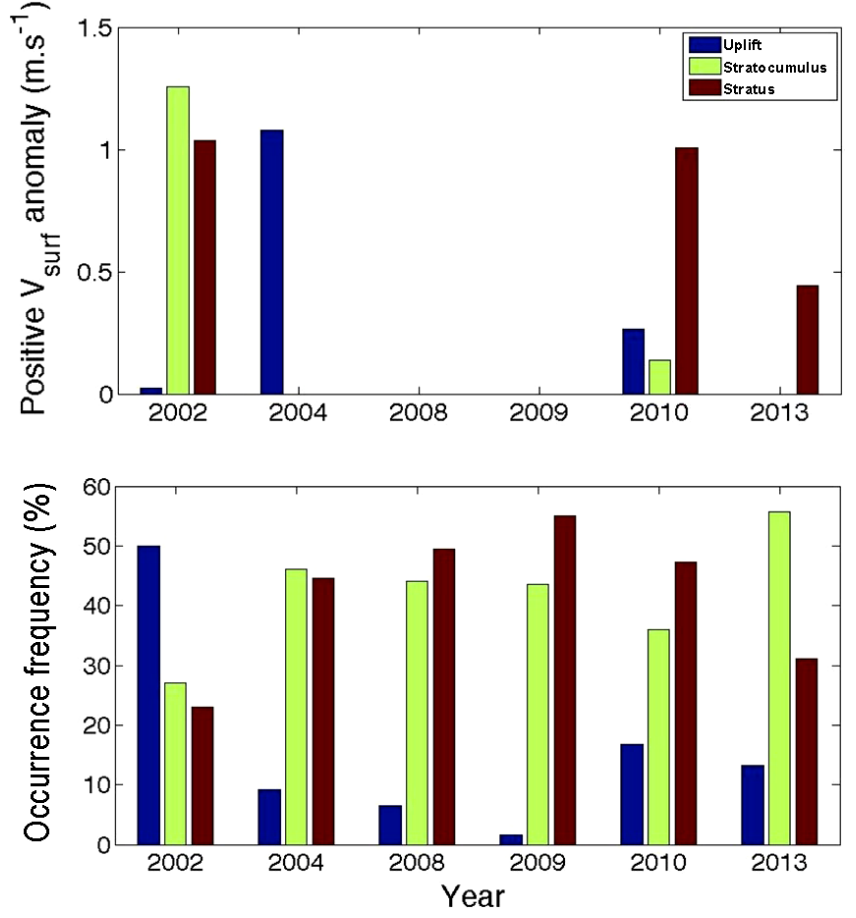

Figure 10. The distribution of occurrence frequency of the different cloud regimes within a given year (bottom panel), and the wind speed anomaly (positive only) for each year and each regime (top panel). Positive wind speed anomalies are calculated with respect to the mean wind speeds for the uplift, stratocumulus, and stratus regimes, which are $7,7.2$, and $7 \mathrm{~ms}^{-1}$, respectively.

cloud condensational (evaporative) processes, and radiative mechanisms.

The explanation of various terms in Eq. (2) can be found in Holton (2004). The measure of the atmospheric stability (Term C) is zero, by definition, for a well-mixed BL because the environmental lapse rate $\left(\Gamma_{\text {env }}\right)$ equals the adiabatic lapse rate $\left(\Gamma_{\text {adiabat}}\right.$; see Sect. 3.2). We inspect processes (sources of vertical motions) that are necessary to make $\Gamma_{\text {env }}$ equal to the $\Gamma_{\text {adiabat. }}$ If we assume that horizontal thermal advection (term $\mathrm{B}$ ) is homogenous leading to uniform changes in the local temperature profile (term A), then it may not influence the atmospheric stability $\left(\Gamma_{\text {env }}\right)$. However, $\Gamma_{\text {env }}$ can change in response to diabatic heating (term $\mathrm{D}$ ), which includes two main sources, viz. surface (sensible and latent) heat fluxes and clouds.

The largely positive temperature gradient $(\Delta T)$ during early fall (Fig. 3b) is favorable for episodes of upward sensible heat flux and rising air parcels which can make $\Gamma_{\text {env }}$ more unstable. (Note that although the surface latent heat fluxes are not measured here, they are typically proportional to the SSHF.) Similarly, Arctic clouds which form due to largescale processes (Herman and Goody, 1976; Morrison et al., 2012; Solomon et al., 2014) can generate vertical mixing due to a combination of condensational warming and cloud-top 
radiative cooling. Now, in the absence of low clouds, the surface fluxes will be the main factor to control $\Gamma_{\text {env }}$ and the BL mixing. This is consistent with our results, which basically show a good correlation between the SSHF and BL height for the cases with near-zero BL cloud thickness (uplift regime in Table 1 and Fig. 7a). On the other hand, when low clouds are observed in the vicinity of well-mixed layers (stratus and stratocumulus regimes in Table 1), a weaker relationship is found to exist between the SSHF and BL height as cloud condensational warming may enhance the height of the surface mixed layer. The shallow BL observed in 2002 is likely due to the lack of occurrence of low clouds during that year (Fig. 8a, b).

Now, let us consider the large-scale environment associated with cloudy Arctic BLs. It appears that CAA leads to stratocumulus cloud formation, whereas stratus clouds occur in a warm and wet environment (Figs. 5 and 6; Sato et al., 2012). One might expect the SSHF contribution to be greater (cloud contribution to be lower) during the former regime due to the larger $\Delta T$ associated with CAA (Table 1). But we find no significant relationship between the BL height and $\Delta T$ as explained in Sect. 4.2. The BL mixing due to SSHF is only favored during strong winds in the stratus regime (Fig. 7b). For the stratocumulus regime, it is possible that the advected cold air sinks to dampen the SSHF-generated mixing but also simultaneously lowers the dew point temperature to favor cloud formation and cloud-generated turbulence. Contrary to our findings, a recent modeling study by Deser et al. (2010) showed that during October to April over an ice-free Arctic Ocean, CAA is nullified by the substantial release of surface heat fluxes with minimal contribution from cloud condensational warming. It is therefore imperative to re-evaluate the role of diabatic heating sources in Arctic climate models, especially check the heightened sensitivity to air-sea temperature gradients. Clearly, cloud-driven turbulence and condensational warming can play a significant role in the Arctic BL. In the future, the attribution of moisture involved in BL cloud condensation processes, including the relative importance of remote vs. local sources, remains to be explored.

\section{Discussions}

\subsection{Non-local relationship between sea ice, BL, and clouds}

While it is clear that the early fall open Arctic Ocean has a deeper well-mixed BL and a higher cloud base compared to its ice-covered counterpart (Sato et al., 2012; Schweiger et al., 2008; Kay and Gettelman, 2009), the role of surface fluxes remains to be explored. The deepest, most convective BL (stratocumulus cloud regime) appears to develop in association with large-scale advection of cold, dry air, with minimum contribution from SSHF (Figs. 5c and 6). But it is possible that latent heating via increased surface moisture fluxes (Boisvert and Stroeve, 2015; Boisvert et al., 2013) contributes to the observed BL and cloud changes. For example, Boisvert and Stroeve (2015) estimated a positive correlation between surface moisture flux and cloud fraction in the Beaufort and Chukchi sea regions during the month of October. However, they did not observe such a relationship in September. In the past, studies have commonly observed that northerly cold-air outbreaks originating from polar ice caps result in roll convection and cloud streets fueled primarily by the substantial input of moisture from the ice-free ocean to the atmosphere (Brümmer, 1999; Brümmer and Pohlmann, 2000; Hartmann et al., 1999). Therefore, in addition to local increases in the surface heat and moisture fluxes, the retreating boundaries of the summer Arctic sea ice are important for frontal dynamics that occur along marginal sea ice zones (Kolstad and Bracegirdle, 2008).

Some model simulations of an ice-free Arctic Ocean suggest that the surface heat fluxes will dominate polar amplification during fall and early winter (Deser et al., 2010; Tietsche et al., 2011; Higgins and Cassano, 2009). Our results suggest that surface fluxes and clouds produce diabatic heating in the Arctic BL and are both highly sensitive to nonlocal dynamical factors. This interaction between dynamic and thermodynamic variables must be duly incorporated in climate models for accurate projections of polar amplification. Moreover, the radiative feedbacks of various cloud types to the darker, ice-free ocean surface also need to be well-represented in climate models.

\subsection{Implications for sea ice recovery mechanisms}

During late summer and early fall, the turbulent heat loss from the ocean is considered important for initiating refreeze processes (Inoue and Hori, 2011; Tietsche et al., 2011). Our study shows that the efficiency of turbulent heat exchange has not increased substantially over the regions that have recently experienced accelerated summer sea ice loss. Thus, we strongly recommend continuing the exploration of mechanisms that contribute to the cooling of the ocean and the recovery of the fast-declining Arctic sea ice.

Model simulations may have a more optimistic representation of the ocean-atmosphere interactions in the dynamic new ice-free Arctic, which appears to be sensitive to the temperature gradient $(\Delta T)$ at the surface (Deser et al., 2010; Tietsche et al., 2011; Schweiger et al., 2008; Higgins and Cassano, 2009). For example, simulations show that the complete loss of summer ice over the Arctic Ocean will be reversed during the following cold season, viz. OctoberDecember, when $\Delta T$ is positive (Tietsche et al., 2011). However, more recent measurements have shown that the ocean heat gained during summer can be sustained over the period of fall and winter without being immediately dissipated to the atmosphere, thereby slowing the recovery of sea ice (Jackson et al., 2010, 2012). Based on our results, it appears 
that conditions of uplift and high surface wind speeds may favor efficient heat dissipation by SSHF, whereas episodes of CAA may favor latent heat fluxes. Nilsson et al. (2001) similarly found that the late summer/early fall turbulent heat fluxes over the Atlantic sector of the open Arctic Ocean can be sensitive to cyclone activity and cloud regimes. These dynamical triggers should be duly considered in BL parameterization schemes and surface layer schemes of climate models while evaluating future scenarios and sea ice recovery mechanisms for the Arctic. The chances of possible irreversible and more permanent feedbacks of sea ice loss also need to be seriously evaluated in models.

\section{Summary}

For the rapidly evolving Arctic region, a comprehensive understanding of ocean-atmosphere interactions and underlying coupling processes is crucial for improving regional and global climate models and their predictability. Current models have significant differences in important physical processes such as the efficiency of turbulent heat transfer from the ocean to the atmosphere (Kolstad and Bracegirdle, 2008; Grønas and Skeie, 1999; Pagowski and Moore, 2001). The primary goal of this study was to evaluate and quantify the role of open-ocean sensible heat flux in Arctic BL turbulence based on multi-year ship-based observations acquired during early fall. The main conclusions are summarized as follows:

- The SSHF during fall is mostly positive owing to the positive ocean-atmosphere temperature differences $(\Delta T)$ over the ice-free ocean. Yet, the instantaneous atmospheric response to enhanced heat fluxes only occurs during specific large-scale (cloud) regimes. It is favored during the uplift (low-pressure) regime $(\sim 15 \%$ of the cases) followed by the stratus cloud (warm subsidence) regime ( $\sim 41 \%$ of the cases). Additionally, the ocean heat dissipation by SSHF is more efficient during episodes of high surface wind speeds compared to increased $\Delta T$.

- Stratus and stratocumulus clouds are frequently observed in the open Arctic BL, prevalent roughly $85 \%$ of the time (Fig. 10). The year 2002 is an exception with low BL cloud thicknesses due to the anomalously low surface pressure conditions. In agreement with previous work (Sato et al., 2012), it is found that stratus clouds are associated with warm air advection and a shallow BL (high stability), whereas stratocumulus clouds result from CAA and have deeper, well-mixed BLs (low stability). Contrary to speculation, the turbulence generated by surface heat fluxes is more strongly favored in the former compared to the latter. The instability associated with the stratocumulus-topped BL is likely caused by cloud-driven (moist adiabatic and radiative) turbu- lent processes and is perhaps enhanced by upward surface moisture fluxes over the open ocean.

- Consistent with previous studies (Sato et al., 2013; Schweiger et al., 2008), it is evident that the BL height has increased over the ice-free Arctic Ocean in recent years (Fig. 8a). However, as suggested by past observations over late-summer sea ice (Tjernström et al., 2004; Shupe et al., 2013; Morrison et al., 2012), its variability is primarily controlled by the atmospheric circulation and low-cloud regime as opposed to surface heat fluxes. The relationship between SSHF and BL height is characterized by strong interannual variability, influenced by both surface wind speeds and cloud regimes. In general, the dynamical forcing appears to dominate the ocean-atmosphere coupling during early fall.

This study highlights the need for comprehensive in situ observations to improve model physics for more reliable projections of the coupled Arctic climate and sea ice in the future. Using available surface and upper-air observations from ship cruises, we provide first-hand insights of the optimal conditions for the SSHF contribution to atmospheric mixing. The relevant coupling mechanisms identified in this study, especially the influence of large-scale circulation patterns on clouds and SSHF, can be incorporated to improve the simulations of sea ice loss in current climate models and to obtain a more realistic view of its long-term effects on Arctic climate. The role of latent heat fluxes and cloud formation was evaluated using proxy measurements; nevertheless, it appears to be rather important for the Arctic BL stability. The regional and seasonal-scale variability in SSHF and BL height warrants further investigation as well, which will be pursued in future studies.

\section{Data availability}

The Arctic Oscillation index values were obtained from the National Oceanic and Atmospheric Administration's Climate Prediction Center using the following webpage: http://www.cpc.ncep.noaa.gov/products/precip/CWlink/ daily_ao_index/ao.shtml.

Acknowledgements. This work is supported by NASA Earth Science GNSS Remote Sensing and Interdisciplinary Research programs. Data used in this study were acquired during the MR02K05 Leg 1, MR04-05, MR08-04, MR09-03 Leg 2, MR10-05 Leg 2, and MR13-06 Leg 1 cruises of R/V Mirai, Japan Agency for Marine-Earth Science and Technology.

Edited by: J.-Y. C. Chiu

Reviewed by: two anonymous referees 


\section{References}

Barton, N. P., Klein, S. A., Boyle, J. S., and Zhang, Y. Y.: Arctic synoptic regimes: Comparing domain-wide Arctic cloud observations with CAM4 and CAM5 during similar dynamics, J. Geophys. Res., 117, D15205, doi:10.1029/2012JD017589, 2012.

Boisvert, L. N. and Stroeve, J. C.: The Arctic is becoming warmer and wetter as revealed by the Atmospheric Infrared Sounder, Geophys. Res. Lett., 42, 4439-4446, doi:10.1002/2015GL063775, 2015.

Boisvert, L. N., Markus, T., and Vihma, T.: Moisture flux changes and trends for the entire Arctic in 2003-2011 derived from EOS Aqua data, J. Geophys. Res.-Oceans, 118, 5829-5843, doi:10.1002/jgrc.20414, 2013.

Bourassa, M. A., Gille, S. T., Jackson, D. L., Roberts, J. B., and Wick, G. A.: Ocean winds and turbulent air-sea fluxes inferred from remote sensing, Oceanography, 23, 36-51, 2010.

Brümmer, B.: Roll and cell convection in wintertime arctic cold-air outbreaks, J. Atmos. Sci., 56, 2613-2636, 1999.

Brümmer, B. and Pohlmann, S.: Wintertime roll and cell convection over Greenland and Barents Sea regions: A climatology, J. Geophys. Res., 105, 15559-15566, 2000.

Curry, J. A., Hobbs, P. V., King, M. D., Randall, D. A., Minnis, P., Isaac, G. A., Pinto, J. O., Uttal, T., Bucholtz, A., Cripe, D. G., Gerber, H., Fairall, C. W., Garrett, T. J., Hudson, J., Intrieri, J. M., Jakob, C., Jensen, T., Lawson, P., Marcotte, D., Nguyen, L., Pilewskie, P., Rangno, A., Rogers, D. C., Strawbridge, K. B., Valero, F. P. J., Williams, A. G., and Wylie, D.: FIRE Arctic Clouds Experiment, B. Am. Meteorol. Soc., 81, 5-29, doi:10.1175/15200477(2000)081<0005:FACE>2.3.CO;2., 2000.

Deser, C., Tomas, R., Alexander, M., and Lawrence, D.: The seasonal atmospheric response to projected Arctic sea ice loss in the late twenty-first century, J. Climate, 23, 333-351, 2010.

Eastman, R. and Warren, S. G.: Interannual Variations of Arctic Cloud Types in Relation to Sea Ice, J. Climate, 23, 4216-4232, 2010.

Fairall, C. W., Bradley, E. F., Rogers, D. P., Edson, J. B., and Young, G. S.: Bulk parameterization of air-sea fluxes in TOGA COARE, J. Geophys. Res., 101, 747-3767, 1996.

Fujiyoshi, Y. and Shimada, K.: R/V Mirai Cruise Report MR02-K05 Leg 1, Japan Agency for Marine-Earth Science and Technology, Yokosuka, Japan, 2002.

Fujiyoshi, Y. and Shimada, K.: R/V Mirai Cruise Report MR04-05, Japan Agency for Marine-Earth Science and Technology, Yokosuka, Japan, 2004.

Grønas, S. and Skeie, P.: A case study of strong winds at an Arctic front, Tellus A, 51, 865-879, 1999.

Hakkinen, S., Proshutinsky, A., and Ashik, I.: Sea ice drift in the Arctic since the 1950s, Geophys. Res. Lett., 35, L19704, doi:10.1029/2008GL034791, 2008.

Hartmann, J., Albers, F., Argentini, S., Bochert, A., Bonafe, U., Cohrs, W., Conidi, A., Freese, D., Georgiadis, T., Ippoliti, A., Kaleschke, L., Lüpkes, C., Maixner, U., Mastrantonio, G., Ravegnani, F., Reuter, A., Trivellone, G., and Viola, A.: Arctic Radiation and Turbulence Interaction Study (ARTIST), Berichte zur Polarforschung (Reports on Polar Research) Alfred Wegener Institute for Polar and Marine Research, Bremerhaven, 305 pp., 1999.
Herman, G. and Goody, R.: Formation and persistence of summertime Arctic stratus clouds, J. Atmos. Sci., 33, 1537-1553, 1976.

Higgins, M. E. and Cassano, J. J.: Impacts of reduced sea ice on winter Arctic atmospheric circulation, precipitation, and temperature, J. Geophys. Res., 114, D16107, doi:10.1029/2009JD011884, 2009.

Holton, J. R.: An introduction to dynamic meteorology. Elsevier Academic Press, 2004.

Inoue, J.: R/V Mirai Cruise Report MR10-05, Japan Agency for Marine-Earth Science and Technology, Yokosuka, Japan, 2010.

Inoue, J.: R/V Mirai Cruise Report MR13-06, Japan Agency for Marine-Earth Science and Technology, Yokosuka, Japan, 2013.

Inoue, J. and Hori, M. E.: Arctic cyclogenesis at the marginal ice zone: A contributory mechanism for the temperature amplification?, Geophys. Res. Lett., 38, L12502, doi:10.1029/2011GL047696, 2011.

Inoue, J. and Yoneyama, K.: R/V Mirai Cruise Report MR09-03, Japan Agency for Marine-Earth Science and Technology, Yokosuka, Japan, 2009.

Inoue, J., Kosović, B., and Curry, J. A.: Evolution of a storm-driven cloudy boundary layer in the Arctic, Bound.-Lay. Meteorol., 117, 213-230, doi:10.1007/s10546-004-6003-2, 2005.

Inoue, J., Enomoto, T., and Kikuchi, T.: Intercomparison of surface heat transfer near the Arctic marginal ice zone for multiple reanalyses: A case study of September 2009, Sola, 7, 57-60, 2011.

Inoue, J., Yamakazi, A., Ono, J., Dethloff, K., Maturilli, M., Neuber, R., Edwards, P., and Yamaguchi, H.: Additional Arctic observations improve weather and sea-ice forecasts for the Northern Sea Route, Sci. Rep., 5, 16868, doi:10.1038/srep16868, 2015.

Jackson, J. M., Carmack, E. C., McLaughlin, F. A., Allen, S. E., and Ingram, R. G.: Identification, characterization, and change of the near-surface temperature maximum in the Canada Basin, 1993-2008, J. Geophys. Res.-Oceans, 115, C05021, doi:10.1029/2009JC005265, 2010.

Jackson, J. M., Williams, W. J., and Carmack, E. C.: Winter sea-ice melt in the Canada Basin, Arctic Ocean, Geophys. Res. Lett., 39, L03603, doi:10.1029/2011GL050219, 2012.

Kalnay, E., Kanamitsu, M., Kistler, R., Collins, W., Deaven, D., Gandin, L., Iredell, M., Saha, S., White, G., Woollen, J., Zhu, Y., Leetmaa, A., Reynolds, R., Chelliah, M., Ebisuzaki, W., Higgins, W., Janowiak, J., Mo, K. C., Ropelewski, C., Wang, J., Jenne, R., and Joseph, D.: The NCEP/NCAR 40-Year Reanalysis Project, B. Am. Meteorol. Soc., 77, 437-471, doi:10.1175/15200477(1996)077<0437:TNYRP>2.0.CO;2, 1996.

Kawaguchi, Y., Nishino, S., and Inoue, J.: Fixed-Point Observation of Mixed Layer Evolution in the Seasonally Ice-Free Chukchi Sea: Turbulent Mixing due to Gale Winds and Internal Gravity Waves, J. Phys. Oceanogr., 45, 836-853, 2015.

Kay, J. E. and Gettelman, A.: Cloud influence on and response to seasonal Arctic sea ice loss, J. Geophys. Res., 114, D18204, doi:10.1029/2009JD011773, 2009.

Klein, S. A., McCoy, R. B., Morrison, H., Ackerman, A. S., Avramov, A., Boer, G. d., Chen, M., Cole, J. N. S., Del Genio, A. D., Falk, M., Foster, M. J., Fridlind, A., Golaz, J.-C., Hashino, T., Harrington, J. Y., Hoose, C., Khairoutdinov, M. F., Larson, V. E., Liu, X., Luo, Y., McFarquhar, G. M., Menon, S., Neggers, R. A. J., Park, S., Poellot, M. R., Schmidt, J. M., Sednev, I., Shipway, B. J., Shupe, M. D., Spangenberg, D. A., Sud, Y. C., Turner, D. D., Veron, D. E., Salzen, K. v., Walker, G. K., Wang, 
Z., Wolf, A. B., Xie, S., Xu, K.-M., Yang, F., and Zhang, G.: Intercomparison of model simulations of mixed-phase clouds observed during the ARM Mixed-Phase Arctic Cloud Experiment. I: single-layer cloud, Q. J. Roy. Meteor. Soc., 135, 979-1002, doi:10.1002/qj.416, 2009.

Kolstad, E. W. and Bracegirdle, T. J.: Marine cold-air outbreaks in the future: an assessment of IPCC AR4 model results for the Northern Hemisphere, Clim. Dynam., 30, 871-885, 2008.

Kurita, N. and Yoneyama, K.: R/V Mirai Cruise Report MR08-04, Japan Agency for Marine-Earth Science and Technology, Yokosuka, Japan, 2008.

Morrison, H., Zuidema, P., Ackerman, A. S., Avramov, A., Boer, G., Fan, J., Fridlind, A. M., Hashino, T., Harrington, J. Y., Luo, Y., Ovchinnikov, M., and Shipway, B.: Intercomparison of cloud model simulations of Arctic mixed-phase boundary layer clouds observed during SHEBA/FIRE-ACE, J. Adv. Model. Earth Syst., 3, M05001, doi:10.1029/2011MS000066, 2011.

Morrison, H., de Boer, G., Feingold, G., Harrington, J., Shupe, M. D., and Sulia, K.: Resilience of persistent Arctic mixed-phase clouds. Nature Geoscience, 5, 11-17, 2012.

Nicholls, S. and Leighton, J.: An observational study of the structure of stratiform cloud sheets: Part I. Structure, Q. J. Roy. Meteor. Soc., 112, 431-460, doi:10.1002/qj.49711247209, 1986.

Nilsson, E. D., Rannik, Ü., and Håkansson, M.: Surface energy budget over the central Arctic Ocean during late summer and early freeze-up, J. Geophys. Res.-Atmos., 106, 32187-32205, 2001.

Pagowski, M. and Moore, G.: A numerical study of an extreme coldair outbreak over the Labrador Sea: sea ice, air-sea interaction, and development of polar lows, Mon. Weather Rev., 129, 47-72, 2001.

Palm, S. P., Strey, S. T., Spinhirne, J., and Markus, T.: Influence of Arctic sea ice extent on polar cloud fraction and vertical structure and implications for regional climate, J. Geophys. Res., 115, D21209, doi:10.1029/2010JD013900, 2010.

Sato, K., Inoue, J., Kodama, Y.-M., and Overland, J. E.: Impact of Arctic sea-ice retreat on the recent change in cloudbase height during autumn, Geophys. Res. Lett., 39, L10503, doi:10.1029/2012GL051850., 2012.
Schweiger, A. J., Lindsay, R. W., Vavrus, S., and Francis, J. A.: Relationships between Arctic sea ice and clouds during autumn, J. Climate, 21, 4799-4810, 2008.

Shupe, M. D., Persson, P. O. G., Brooks, I. M., Tjernström, M., Sedlar, J., Mauritsen, T., Sjogren, S., and Leck, C.: Cloud and boundary layer interactions over the Arctic sea ice in late summer, Atmos. Chem. Phys., 13, 9379-9399, doi:10.5194/acp-139379-2013, 2013.

Smedsrud, L. H., Sirevaag, A., Kloster, K., Sorteberg, A., and Sandven, S.: Recent wind driven high sea ice area export in the Fram Strait contributes to Arctic sea ice decline, The Cryosphere, 5, 821-829, doi:10.5194/tc-5-821-2011, 2011.

Solomon, A., Shupe, M. D., Persson, O., Morrison, H., Yamaguchi, T., Caldwell, P. M., and de Boer, G.: The Sensitivity of Springtime Arctic Mixed-Phase Stratocumulus Clouds to SurfaceLayer and Cloud-Top Inversion-Layer Moisture Sources, J. Atmos. Sci., 71, 574-595, doi:10.1175/JAS-D-13-0179.1, 2014.

Taylor, P. C., Kato, S., Xu, K.-M., and Cai, M.: Covariance between Arctic sea ice and clouds within atmospheric state regimes at the satellite footprint level, J. Geophys. Res.-Atmos., 120, 1265612678, doi:10.1002/2015JD023520, 2015.

Tietsche, S., Notz, D., Jungclaus, J. H., and Marotzke, J.: Recovery mechanisms of Arctic summer sea ice, Geophys. Res. Lett., 38, L02707, doi:10.1029/2010GL045698, 2011.

Tjernström, M., Leck, C., Persson, P. O. G., Jensen, M. L., Oncley, S. P., and Targino, A.: The summertime Arctic atmosphere: Meteorological measurements during the Arctic Ocean Experiment 2001, B. Am. Meteorol. Soc., 85, 1305-1321, doi:10.1175/BAMS-85-9-1305, 2004.

Wu, D. L. and Lee, J. N.: Arctic low cloud changes as observed by MISR and CALIOP: Implication for the enhanced autumnal warming and sea ice loss, J. Geophys. Res., 117, D07107, doi:10.1029/2011JD017050, 2012. 